\title{
What we know about paracentesis induced circulatory dysfunction?
}

\author{
Jeong Han Kim \\ Department of Internal Medicine, Konkuk University School of Medicine, Seoul, Korea
}

Keywords: Liver Cirrhosis; Ascites; Paracentesis

\section{See Article on Page 365}

Ascites is the most common complication in liver cirrhosis (LC), occurring in $60 \%$ of the patients with compensated LC within 10 years. ${ }^{1}$ Therapeutic paracentesis is an effective treatment for tension-type ascites, because it relieves the symptom more quickly than diuretics and shortens hospitalization. ${ }^{2}$ Refractory ascites is defined as fluid overload that is not controlled despite restriction of sodium intake and the maximum dose of diuretics, and recurs rapidly after paracentesis. ${ }^{3}$ Large volume paracentesis (LVP) has become the first line of treatment for patients with severe and refractory ascites. ${ }^{4}$ Paracentesis-induced circulatory dysfunction (PICD) occurs as a complication of LVP. Though PICD remains clinically silent, it is an important predictor of mortality in patients with severe ascites treated by LVP. ${ }^{5}$ A recent meta-analysis concluded that PICD is associated with a high rate of ascites recurrence, development of hepatorenal syndrome, dilutional hyponatremia, and high mortality. ${ }^{6}$ PICD is definitively diagnosed through laboratory results, with increases of more than $50 \%$ of baseline plasma rennin activity to $>4 \mathrm{ng} / \mathrm{mL} / \mathrm{h}$ on the $5^{\text {th }}$ to $6^{\text {th }}$ days after paracentesis. $^{5,7}$

The exact pathophysiology of PICD is not entirely understood.
PICD was initially thought to occur secondary to fluid shifting after paracentesis, resulting in decreased circulating volume. ${ }^{8}$ Additional studies demonstrated that decreased systemic vascular resistance also plays an essential role in PICD. ${ }^{7,910}$ The resulting effective hypovolemia due to arteriolar vasodilation in turn leads to a prolonged activation of the sympathetic nervous system and the rennin-angiotensin-aldosterone pathway. Increased plasma rennin activity in particular is characteristic of PICD, however general hyporesponsiveness to vasoconstrictors in the setting of cirrhosis decreases the ability to compensate for the accentuated vasodilation. ${ }^{11}$

One of the simplest ways to prevent PICD is to limit the volume of fluid removed to 5 to $6 \mathrm{~L}$ at a time..$^{5,12,13}$ The incidence of PICD approaches $80 \%$ when a LVP is performed without additional therapeutic management; the incidence is reduced to 15 to $35 \%$ when volume expanders are used. ${ }^{14}$ Of all the plasma expanders, human albumin infusion is considered as the best option due to its long half-life of 21 days. In addition to its oncotic value, albumin has antioxidant, detoxification, immunoprotective, drug binding and delivery properties. ${ }^{15,16}$ One recent meta-analysis concluded that albumin was superior to other volume expanders and alternative treatments in decreasing the risk of PICD, hyponatremia, and mortality. ${ }^{6}$ A separate recent meta-analysis demonstrated the ben-

\section{Abbreviations:}

LC, liver cirrhosis; LVP, large volume paracentesis; PICD, paracentesisinduced circulatory dysfunction

\section{Corresponding author : Jeong Han Kim}

Department of Internal Medicine, Konkuk University School of Medicine, Konkuk University Medical Center, 120-1 Neungdong-ro, Hwayang-dong, Gwangjin-gu, Seoul 05030, Korea

Tel: +82-2-2030-7764, Fax: +82-2-2030-5029

E-mail:93haan@hanmail.net 
efit of albumin administration in decreasing the incidence of PICD after paracentesis as well as morbidity and mortality in patients with any type of infection. ${ }^{17}$

Current guidelines recommend albumin infusion when LVP $>5$ liter is removed as it prevents $85 \%$ of cirrhotic patients from developing PICD. ${ }^{18,19}$ Albumin therapy has also been shown to improve survival in cirrhotic patients with spontaneous bacterial peritonitis by reducing incidence of renal impairment. ${ }^{20}$ The American Association for the Study of Liver Diseases guidelines state that it is reasonable but not mandatory to give 6 to $8 \mathrm{~g}$ of albumin per liter of ascites removed when more than $5 \mathrm{~L}$ are removed. ${ }^{19}$

Reducing the flow rate of fluid removed during the paracentesis is also theorized to decrease the incidence of PICD. ${ }^{21}$ Some physicians have tried this method to prevent PICD in real clinical practice. However, clinical evidence of this approach is lacking. In the current issue, Elsabaawy et al. ${ }^{22}$ evaluated the impact of paracentesis flow rate on PICD. Sixty patients with refractory ascites underwent LVP randomized into 3 groups and controlled with different flow rate extraction each. Results showed flow rate was not significant factor of PICD development and only female was a predictor of PICD. Authors concluded that paracentesis flow rate did not correlate with PICD development. Although there is limitation of small scale, this study has strength of prospective design. In addition to need of larger scale study, author did not reveal the reason why female was only significant predictor of PICD development. In the era of albumin infusion during LVP, flow rate of parecentesis may do not matter. In this point of view, one question is still remained. Will flow rate not impact on PICD development even without albumin infusion during LVP?

In conclusion, this study showed that flow rate of paracentesis did not correlate with PICD development. To date, there is little data about this correlation. Therefore, such information may be useful to clinician. Further well designed larger research is needed to confirm this result.

\section{Conflicts of Interest}

The author has no conflicts to disclose.

\section{REFERENCES}

1. Ginés $P$, Quintero $E$, Arroyo V, Terés J, Bruguera $M$, Rimola $A$, et al. Compensated cirrhosis: natural history and prognostic factors. Hepatology 1987;7:122-128.

2. Suk KT, Baik SK, Yoon JH, Cheong JY, Paik YH, Lee CH, et al. Revi- sion and update on clinical practice guideline for liver cirrhosis. Korean J Hepatol 2012;18:1-21.

3. Arroyo V, Ginès P, Gerbes AL, Dudley FJ, Gentilini P, Laffi G, et al. Definition and diagnostic criteria of refractory ascites and hepatorenal syndrome in cirrhosis. International Ascites Club. Hepatology 1996;23:164-176.

4. Moore KP, Aithal GP. Guidelines on the management of ascites in cirrhosis. Gut 2006;55(Suppl 6):vi1-vi12.

5. Ginès A, Fernández-Esparrach $G$, Monescillo A, Vila C, Domènech E, Abecasis $R$, et al. Randomized trial comparing albumin, dextran 70, and polygeline in cirrhotic patients with ascites treated by paracentesis. Gastroenterology 1996;111:1002-1010.

6. Bernardi M, Caraceni P, Navickis RJ, Wilkes MM. Albumin infusion in patients undergoing large-volume paracentesis: a meta-analysis of randomized trials. Hepatology 2012;55:1172-1181.

7. Sola-Vera J, Such J. Understanding the mechanisms of paracentesisinduced circulatory dysfunction. Eur J Gastroenterol Hepatol 2004;16:295-298.

8. Saló J, Ginès A, Ginès P, Piera $C$, Jiménez W, Guevara $M$, et al. Effect of therapeutic paracentesis on plasma volume and transvascular escape rate of albumin in patients with cirrhosis. J Hepatol 1997:27:645-653.

9. Ruiz-del-Arbol L, Monescillo A, Jimenéz W, Garcia-Plaza A, Arroyo $V$, Rodés J. Paracentesis-induced circulatory dysfunction: mechanism and effect on hepatic hemodynamics in cirrhosis. Gastroenterology 1997;113:579-586.

10. Vila MC, Solà R, Molina L, Andreu M, Coll S, Gana J, et al. Hemodynamic changes in patients developing effective hypovolemia after total paracentesis. J Hepatol 1998;28:639-645.

11. Ryan J, Sudhir K, Jennings G, Esler M, Dudley F. Impaired reactivity of the peripheral vasculature to pressor agents in alcoholic cirrhosis. Gastroenterology 1993;105:1167-1172.

12. Peltekian KM, Wong F, Liu PP, Logan AG, Sherman M, Blendis LM. Cardiovascular, renal, and neurohumoral responses to single largevolume paracentesis in patients with cirrhosis and diuretic-resistant ascites. Am J Gastroenterol 1997;92:394-399.

13. Sola-Vera J, Miñana J, Ricart E, Planella M, González B, Torras X, et al. Randomized trial comparing albumin and saline in the prevention of paracentesis-induced circulatory dysfunction in cirrhotic patients with ascites. Hepatology 2003;37:1147-1153.

14. Lindsay AJ, Burton J, Ray CE Jr. Paracentesis-induced circulatory dysfunction: a primer for the interventional radiologist. Semin Intervent Radiol 2014;31:276-278.

15. Jalan R, Bernardi M. Effective albumin concentration and cirrhosis mortality: from concept to reality. J Hepatol 2013;59:918-920.

16. Garcia-Martinez R, Caraceni P, Bernardi M, Gines P, Arroyo V, Jalan R. Albumin: pathophysiologic basis of its role in the treatment of cirrhosis and its complications. Hepatology 2013;58:1836-1846. 
17. Kwok CS, Krupa L, Mahtani A, Kaye D, Rushbrook SM, Phillips MG, et al. Albumin reduces paracentesis-induced circulatory dysfunction and reduces death and renal impairment among patients with cirrhosis and infection: a systematic review and meta-analysis. Biomed Res Int 2013;2013:295153.

18. European Association for the Study of the Liver. EASL clinical practice guidelines on the management of ascites, spontaneous bacterial peritonitis, and hepatorenal syndrome in cirrhosis. J Hepatol 2010;53:397-417.

19. Runyon BA. Introduction to the revised American Association for the Study of Liver Diseases Practice Guideline management of adult patients with ascites due to cirrhosis 2012. Hepatology 2013;57:16511653.
20. Sort P, Navasa M, Arroyo V, Aldeguer X, Planas R, Ruiz-del-Arbol L, et al. Effect of intravenous albumin on renal impairment and mortality in patients with cirrhosis and spontaneous bacterial peritonitis. $\mathrm{N}$ Engl J Med 1999;341:403-409.

21. Coll S, Vila MC, Molina L, Gimenez MD, Guarner C, Solà R. Mechanisms of early decrease in systemic vascular resistance after total paracentesis: influence of flow rate of ascites extraction. Eur J Gastroenterol Hepatol 2004;16:347-353.

22. Elsabaawy MM, Abdelhamid SR, Alsebaey A, Abdelsamee E, Obada $M A$, Salman TA, et al. The impact of paracentesis flow rate in patients with liver cirrhosis on the development of paracentesis induced circulatory dysfunction. Clin Mol Hepatol 2015;21:365-371. 